
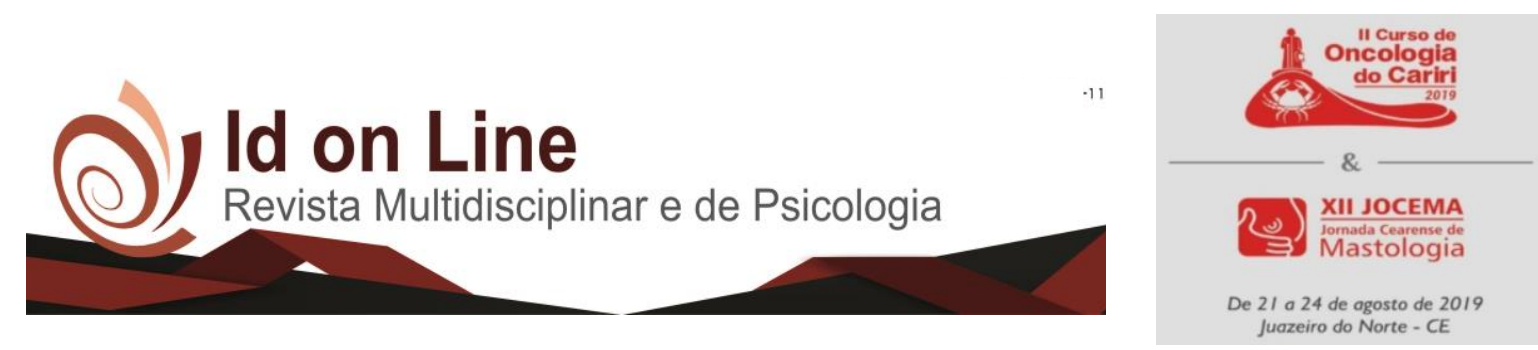

\title{
A IMPORTÂNCIA DA IMUNOTERAPIA NO TRATAMENTO DO CÂNCER DE PULMÃO: UMA REVISÃO BIBLIOGRÁFICA
}

\author{
SILVA, Bárbara Lacerda Menezes ${ }^{1}$; FREIRE, Mariana Nogueira Duarte ${ }^{2}$; RIBEIRO, Ana Vitória Gonçalves ${ }^{3}$; ; \\ ARAÚJO, Itamar Alves ${ }^{4}$; BEZERRA,Thais Parente ${ }^{5}$;ARAÚJO, Moises Ederlanio Tavares ${ }^{6}$.
}

Introdução: A importância da busca por novas abordagens de tratamentos e prevenção do câncer de pulmão é evidente perante aos indicadores de incidência e de óbito caudados por essa doença. As principais modalidades de tratamentos desse tipo de câncer, a exemplo da quimioterapia, radioterapia e cirugia, nem sempre se mostram eficientes, assim, emerge desse cenário uma modalidade de tratamento voltada a estimular o sistema imunológico, denominado imunoterapia, no combate dessa doença. Assim é possível evidenciar a importância do tratamento do câncer de pulmão dependendo da estratégia de tratamento e do estágio do desenvolvimento tumoral, sendo a imunoterapia uma escolha de suma relevância que visa combater essa patologia. Objetivo: Apresentar a importância do tratamento com imunoterapia em pacientes com câncer de pulmão. Método: Utilizou-se para realização do trabalho uma revisão bibliográfica, na qual foram pesquisados artigos científicos publicados entre os anos de 2007 e 2017 nas bases de dados: Pubmed, Scielo e Medline. Na pesquisa, utilizaram-se os descritores imunoterapia, câncer de pulmão na plataforma DeCS. Foram selecionados dezesseis artigos, em idiomas português e inglês, dos quais, após a leitura de seus respectivos resumos, foram excluídos dez por não condizerem com a temática em questão, tendo usado seis para construção do trabalho. Resultados: O anticorpo monoclonal anti-PD-1 nivolumabe foi aprovado no tratamento do câncer de pulmão de células pequenas metastático. A utilização desse anticorpo é baseada na coorte de pacientes com câncer de pulmão de células pequenas incluídos no estudo de fase I/II CheckMate-032. Dentre os 109 pacientes avaliados que apresentaram previamente progressão a $\geq 2$ linhas de tratamento sistêmico (sendo uma delas quimioterapia baseada em platina e algum outro tratamento), a taxa de resposta alcançada com o uso de nivolumabe foi de $12 \%$. Entre os respondedores, a duração mediana da resposta foi de 17,9 meses. Conclusão: Assim, fica evidente que a imunoterapia como estratégia de tratamento vem se mostrando mais eficiente em conter o crescimento tumoral, quando comparada à quimioterapia .Esta aprovação marca uma nova era para os pacientes com câncer de pulmão, após várias décadas sem avanços no tratamento. Apesar da taxa de resposta de $12 \%$, chama atenção a qualidade destas respostas, que são duradouras, independentes da sensibilidade.

Palavras-chave: Quimioterapia, Imunoterapia,Câncer de pulmão.

\footnotetext{
${ }^{1}$ Acadêmica de medicina na Faculdade de Medicina Estácio de Juazeiro do Norte; barbaralacerdamenezesdasilva@outlook.com.br

${ }^{2}$ Acadêmica do curso de medicina na Faculdade de Medicina Estácio de Juazeiro do Norte; mari.duarte10@ hotmail.com.br

${ }^{3}$ Acadêmica do curso de medicina na Faculdade de Medicina Estácio de Juazeiro do Norte; anavitorialindinha@hotmail.com.br

${ }^{4}$ Acadêmica do curso de medicina na Faculdade de Medicina Estácio de Juazeiro do Norte; itamararaujo15@gmail.com.br

${ }^{5}$ Acadêmica do curso de medicina na Faculdade de Medicina Estácio de Juazeiro do Norte; thaispbezerra@ hotmail.com.br

${ }^{6}$ Orientador, médico cirurgião geral pelo Hospital Regional do Cariri e Cirurgião torácico pelo Hospital de Messejana Dr. Carlos

Alberto Studart Gomes ; e- mail:moises_ederlanio@yahoo.com.br
} 


\section{Referências:}

DE LEYN P, DOOMS C, KUZDZAL J, et al. Preoperative mediastinal lymph node staging for non-small cell lung cancer: 2014 update of the 2007 ESTS guidelines. Transl Lung Cancer Res. 2014 Aug; 3(4): 225-233.

ARRIAGADA R, BERGMAN B, DUNANT A, LE CHEVALIER T, PIGNON JP, VANSTEENKISTE J. Cisplatinbasedadjuvant chemotherapy in patients with completely resected non-small-cell lungcancer. N Engl J Med. Jan 22 2004;350(4):351-360.

FOSSELLA F, PEREIRA JR, VON PAWEL J, ET AL. Randomized, multinational, phase III study of docetaxel plus platinum combinations versus vinorelbine plus cisplatin for advanced nonsmall-cell lung cancer: the TAX 326 study group. J Clin Oncol. Aug 15 2003;21(16):3016-3024.

DOUILLARD JY, ROSELL R, DE LENA M, et al. Adjuvant vinorelbine plus cisplatin versus observation in patients with completely resected stage IB-IIIA non-small-cell lung cancer(Adjuvant Navelbine International Trialist Association [ANITA]): a randomised controlled trial. Lancet Oncol. Sep 2006;7(9):719-727.

WINTON T, LIVINGSTON R, JOHNSON D, et al. Vinorelbine plus cisplatin vs. observation in resected nonsmall-cell lung cancer. N Engl J Med. Jun 23 2005;352(25):2589-2597.

KREUTER M, VANSTEENKISTE J, FISHCER JR, et al. Randomized phase 2 trial on refinement of early-stage NSCLC adjuvant chemotherapy with cisplatin and pemetrexed versus cisplati and vinorelbine: the TREAT study. Ann Oncol 2013(24):986-992. 